\title{
Explorações sobre práticas metodológicas na pesquisa em comunicação
}

\section{RESUMO}

A proposta deste artigo é refletir sobre a metodologia na pesquisa de comunicação, a partir do exame de práticas concretas que alicerçam o fazer investigativo. Para realizar este objetivo busco, inicialmente, delinear algumas perspectivas que orientam a reflexão relativa à metodologia como dimensão constitutiva do processo de construção da pesquisa para, em seguida, caracterizar e refletir sobre o sentido de certas práticas constitutivas da ação investigativa. Especificamente, são objeto de exame as práticas de pesquisa da pesquisa, teórica, metodológica, de contextualização e exploratória.

\section{PALAVRAS-CHAVE \\ metodologia \\ pesquisa em comunicação \\ práticas na pesquisa}

\begin{abstract}
The purpose of this article is to think about the methodology in communication research thingh the examination of concrete practices that are the base of the investigative process. To achieve this goal I initially outlined some perspectives that guide the debate about methodology as constitutive of the construction process of the research, Then, I'll characterize it and reflected on the meaning of certain constitutive practices of investigative action. Specifically, the subjects studied are the practices of research of the research, as well as theoretical, methodological, contextualization and exploratory research.
\end{abstract}

\section{KEY WORDS}

methodology

research in communication

practices in research
Focalizando a dimensão metodológica da pesquisa em comunicação em seu fazer concreto e dando seqüência a reflexões anteriores sobre esta temática ${ }^{1}$ busco, neste artigo, identificar e refletir sobre o sentido de certas práticas constitutivas do processo investigativo. Para chegar a este objetivo procuro, num primeiro movimento, esboçar algumas linhas de reflexão relacionadas mais especificamente à metodologia enquanto dimensão da práxis da pesquisa que, a meu ver, se vinculam ao sentido das práticas que busco, num segundo movimento, caracterizar e pensar: as pesquisas de pesquisa teórica, metodológica, exploratória e de contextualização.

Alimentam as reflexões aqui empreendidas propostas de autores, situados em diferentes campos disciplinares, que considero fecundas para pensar a dimensão metodológica na pesquisa em comunicação; práticas coletivas e individuais de pesquisa por mim experienciadas; trabalho docente em disciplinas de metodologia e em orientações de mestrado e de doutorado e, também, a participação em grupos de pesquisa, em processos de construção de reflexão metodológica de investigações. Estes referentes me instigam e me alimentam no exercício de pensar a metodologia enquanto dimensão pratica$d a$ na pesquisa comunicacional.

\section{A metodologia enquanto dimensão inscrita na prática investigativa: delineamentos}

Desde o foco que me interessa pensar neste artigo, a saber, em sua inscrição nas práticas investigativas, a metodologia pode ser pensada como dimensão que norteia, orienta, encaminha os processos de construção da pesquisa, em todos os seus níveis; como instância corporificada em fazeres, operações, experimentações e procedimentos que vão dando feição ao objeto do conhecimento, que vão se inscrevendo em lógicas atuantes na captura e fabricação pensada deste objeto.

Esta perspectiva se nutre de concepções de outros pesquisadores. Lopes (1990) trabalha a noção de metodologia na pesquisa para pensá-la, no plano da prática, como conjunto de decisões e opções particulares realizadas ao longo de um processo de investigação; como lógica em ato que orienta a dinâmica real da pesquisa. Esta autora insiste na necessidade de instituir a reflexão como fundamento da prática metodológica, tal como Bachelard (1977). Maldonado (2002, p.3) também concebe o método como instância que "constrói caminhos, definindo planos, sistematizações, operacionalizações, testes, explorações, observações, experimentações, estratégias e táticas que, no caso da ciência, têm por objetivo produzir conhecimento sobre fenômenos e processos do cosmos".

Operamos com a metodologia ao fazer pesquisa e essa 
operação pode se realizar de modo mais ou menos consciente nesta caminhada. O desafio é torná-la consciente, posto que a dimensão do método configura o objeto e responde também pelo tipo de conhecimento que se produz, por suas limitações e seu alcance (BACHELARD, 1997; BOURDIEU et al. 1999; LOPES, 1990). Desde aí, se pode vislumbrar como esta dimensão não pode ser negligenciada na pesquisa, o que me leva a pensar, com Bachelard (1977), que cada operação investigativa deve ser submetida à reflexão e interrogação, nos seus detalhes mais ínfimos ${ }^{2}$. A metodologia, no concreto da pesquisa, pode ser vista como construção pensada, refletida dos objetos. É importante lembrar que esta construção se realiza num campo científico, no caso, o da Comunicação - o que, a meu ver, não exclui relações e interfaces com outros campos, já que nossos objetos são multidimensionais e complexos, exigentes de formulações também complexas para apreendê-los, nas quais se faz necessária a confluência de saberes disciplinares, apropriados e repensados para responder aos objetos comunicacionais ${ }^{3}$. E, não obstante sua "juventude", este campo já dispõe de um "acervo" de métodos, procedimentos, reflexões, sistematizações, estruturações constituídos na sua caminhada histórica que não podem ser negligenciados pelo pesquisador que inicia uma nova investigação (LOPES, 1990).

É mister reconhecer que o campo científico é um lugar sociológico de disputas e de tensões (BOURDIEU, 1994), mas é importante lembrar também que a produção do conhecimento tem uma dimensão coletiva. A construção de novos conhecimentos se faz em relação com este saber acumulado, por rupturas como vê Bachelard (1977), mas também por continuidades.

Sendo assim, toda pesquisa que se compromete efetivamente com o avanço do conhecimento necessita colocar-se em diálogo tenso com a produção do campo onde se insere (e de outros afins) no que concerne à problemática investigada, nos vários âmbitos da sua fabricação (domínios epistemológicos, teóricos, metódicos, técnicos). Diálogo na tensão implica operar com e contra - com as proposições que se mostrem férteis para laborar na problemática investigada; contra o que pode obliterar a construção e captura do fenômeno investigado - por empenho da ação enérgica do pensamento polêmico (BACHELARD, 1977), da reflexão sensibilizada e alimentada pelas solicitações e resistências dos objetos concretos. Sim, porque ao olhar atento, aberto e reflexivo, os objetos concretos oferecem resistências também, restos que não se deixam enquadrar e que, se captados, recolhidos e pensados com cautela, podem fecundar a produção do conhecimento, desestabilizar conceitos e exigir empenhos na construção de concepções que busquem efetivamente contemplá-los.

Bachelard (1977), na sua polêmica contra o empirismo e o positivismo imperantes na ciência do século XIV, adverte que a observação da realidade concreta, por si só, não é base suficiente para fundar a fabricação do conhecimento científico; que a compreensão do mundo concreto/empírico necessita do pensamento, da teoria para realizar-se. Nem racionalidade vazia nem empirismo desconexo dariam conta da lógica que preside a construção do conhecimento, cuja base seria a profunda união e conexão de dois pólos filosóficos na ação científica: razão e empiria (ou teoria e dado empírico) constituindo, nesta ação, uma mentalidade abstrato-concreta. Tal lógica ele caracterizou como um racionalismo concreto, solidário da experiência, aberto para receber novas determinações. O objeto de investigação lembra-nos este autor, é construído; sua captura/compreensão necessita da elaboração de uma problemática, que se concretiza na dialética entre estes dois movimentos.

Quando observamos explicitações metodológicas de pesquisadores como Mills e Certeau, identificamos também concepções semelhantes às de Bachelard, no que se refere à construção do objeto científico: lógicas de abstração e de concretização confluem na práxis da pesquisa, dando sustentação à construção dos objetos investigados. A explicitação dos processos metodológicos da pesquisa publicada em $A$ invenção do Cotidiano (CERTEAU 1994; CERTEAU, GIARD E MAYOL, 1996) é rica neste sentido e permite ver como se instituem nos programas de pesquisa coletivos movimentos concretos de pesquisa teórica e empírica: Voluntariamente, em sua adequação a seu objeto concreto, a análise aqui se dedica a um incessante vaivém do teórico para o concreto, e depois do particular e do circunstancial ao geral (GIARD, 1994, p.21).

As proposições de Mills (1975) sobre a prática da pesquisa pensada como artesanato intelectual - explicitadas no Apêndice do livro A imaginação sociológica, intitulado Do artesanato intelectual - também são estimulantes para pensar a importância de praticar a pesquisa como ofício e ter domínio do seu processo de construção. Na riqueza das descrições de suas práticas, vemos convergirem processos de pesquisa teórica, metodológica e empírica na construção dos projetos de investigação.

Compartilhando com estes autores no sentido de pensar que a construção do objeto científico necessita da profunda convergência destes pólos (abstrato/concreto), cabe perguntar: Como fazer estas lógicas operarem efetivamente no processo de construção da pesquisa comunicacional? Que práticas possibilitariam a realização desta perspectiva abstrato-concreta? Que sentidos elas teriam neste processo? Estas indagações me acompanham na tentativa de identificar, caracterizar e refletir sobre certas práticas constitutivas da processualidade da investigação.

\section{Práticas metodológicas na construção da pesquisa}

Considerando as reflexões até aqui empreendidas, busco agora caracterizar e refletir sobre práticas que potencializam a realização da necessária tensão concreto/ pensamento no domínio da investigação concreta. As sistematizações que busco empreender relativas a estas práticas são profundamente nutridas por conhecimentos advindos de vivências concretas de investigação (grupos de pesquisa, orientações, caminhadas individuais 
etc.) potencializadoras de experimentações, estruturações, testes e reflexões metodológicas na construção em pesquisas de comunicação ${ }^{4}$ e valem-se também de experiências e de propostas de outros pesquisadores/autores como Bachelard (1977), Mills (1975), Bourdieu et al. (1999), Certeau (1994), Lopes (1990; 2002) e Maldonado (2002a, 2002b; 2006), entre outros.

Estas experiências e reflexões me permitem pensar/ propor que as práticas de pesquisas teórica, metodológica, da pesquisa, de contextualização e exploratória ${ }^{5}$ são movimentos importantes no processo de fabricação da pesquisa. E que, na confluência destes movimentos, sempre comprometidos com a construção reflexiva de uma problemática, pode constituir-se uma "mentalidade abstrato-concreta" (em termos bachelardianos). Estas operações metodológicas precisam, portanto, ser trabalhadas concomitante e articuladamente - de modo a colocar o sujeito investigador pensante no centro da tensão entre estes movimentos. Na seqüência, passo a examinar mais concretamente cada uma destas práticas e a refletir sobre seu sentido no processo de construção da pesquisa.

\section{a) Pesquisa da pesquisa}

O percurso de desenvolvimento de pesquisas do campo da comunicação (no Brasil e em outros países) se materializa num "acervo" de contribuições concretas para o entendimento dos fenômenos comunicacionais. Tais pesquisas sintetizam, muitas vezes, avanços teóricos e metodológicos importantes para o campo. A pesquisa da pesquisa torna-se, por conseguinte, uma prática relevante para tomar contato com esta produção, a fim de que as novas investigações contemplem e considerem estes desenvolvimentos e aquisições e busquem efetivamente avançar com e a partir deles.

Realizar pesquisa da pesquisa implica trabalhar concretamente com investigações produzidas no campo (e em áreas de interface) relacionadas ao problema/objeto, para fazer desta produção elemento ativo na sua elaboração. Tal movimento exige desde ações mais operativas de levantamento das pesquisas quanto trabalho alentado de reflexão e desconstrução, que permita ao pesquisador empreender apropriações, reformulações e alargamentos de proposições, em vários níveis. Um mapeamento geral das pesquisas realizadas é importante para situar-se neste processo, e orientará o trabalho de reflexão aprofundada daquelas que se mostrem relevantes. Programas de pesquisa da pesquisa devem então ser elaborados para que este movimento se concretize efetivamente na investigação.

Esta operação metodológica oferece elementos para a elaboração da problemática, bem como para a autoconstrução do pesquisador, na medida em que potencializa o aprendizado metodológico pelo trabalho alentado de exame destas investigações, contribuindo para o alargamento da capacidade de pensar/projetar a pesquisa de maneira consciente. A pesquisa da pesquisa também permite visualizar os problemas já enfrentados na investiga- ção, os conhecimentos obtidos e daí trabalhar na formulação de questionamentos que tragam à luz novas dimensões dos fenômenos comunicacionais. Fundamenta o trabalho concreto de construção da relevância científica da pesquisa, permitindo situar, problematizar e afirmar a contribuição que vai oferecer ao conjunto de conhecimentos do campo relacionados ao problema/objeto investigado.

Na dimensão teórica, esta operação contribui para pensar possibilidades e propostas que se mostrem férteis para aprofundamento na pesquisa em construção, assim como para visualizar insuficiências neste nível que podem ser objeto de superação. No plano propriamente metodológico, pode oferecer inspirações e elementos para arquitetar métodos e procedimentos constitutivos da investigação em processo ${ }^{6}$. Observando o sentido deste movimento, vemos que oferece elementos teóricos, metodológicos, contextuais e empíricos para a elaboração da problemática. Entrar em contato com a produção do campo e trabalhar com ela (na tensão) é, portanto, uma prática fundamental para sustentar efetivos avanços na produção de conhecimentos do campo.

\section{b) Pesquisa teórica}

Ao refletir sobre a ruptura histórica de amplas proporções que estamos vivendo com a globalização, Ianni (1998) nos convida a pensar sobre os desafios colocados às ciências sociais. Ele argumenta que as metamorfoses do objeto, alterando simultaneamente as possibilidades que se abrem ao sujeito da reflexão, coloca novos desafios epistemológicos, metodológicos e teóricos para as ciências sociais. O que está em jogo, pensando especificamente a questão teórica, é a capacidade das formulações e dos conceitos darem conta da nova realidade e, neste caso, muito do conhecimento acumulado deve ser submetido à crítica e alargado.No campo da comunicação, ao desafio de pensar como a globalização impacta a configuração dos objetos do campo soma-se outro, de grande envergadura: a necessidade de pensar e compreender o processo de midiatização - que remete às transformações socioculturais potenciadas pela expansão das mídias na sociedade, ao caráter configurador da técnica, do ecossistema midiático nos desenhos das interações, dos funcionamentos institucionais, dos campos, das configurações espaço-temporais das sociedades, da experiência, da produção de sentido, entre outras dimensões (Mata, 1999; Verón, 1997; Martín Barbero, 2004; Sodré, 2006). O entendimento deste processo, articulado ao da globalização, vem nos desafiar no sentido de produzirmos desenvolvimentos teóricos para dele dar conta. A meu ver aí se pode ver o lugar de fronteira onde estamos operando, que nos impõe a tarefa de refletirmos vigorosamente sobre as teorizações estabelecidas para produzir novas sínteses, novos arranjos teóricos capazes de iluminar a compreensão deste processo.

Neste lugar de fronteira em que estamos trabalhando, é importante considerar que temos desenvolvimentos em relação a esta noção que não estão acabados, mas em 
franco processo de construção. Temos, além disso, elaborações teóricas complexas que foram se fazendo na história do nosso campo e que ainda conservam fecundidade o desafio é submetê-las à crítica e a reformulações necessárias para dar conta desta nova realidade comunicacional. A complexidade deste processo, que não opera fora dos contextos sociais, econômicos, políticos, culturais, psíquicos vigentes no concreto histórico, exige novas sínteses e repõe na agenda a necessidade de nos alimentarmos de formulações de outros campos que nos possam ser úteis.

$\mathrm{Na}$ fabricação concreta das pesquisas em comunicação, lembra-nos Maldonado (2002, 2006), a construção dos objetos de investigação solicita, portanto, empenho na elaboração teórica das problemáticas. Redes de conceitos trabalhados em articulação entre si e solidárias do concreto investigado precisam ser configuradas o que, no plano das ações de construção, demanda fortes investimentos em pesquisa teórica.

Trabalhar em pesquisa teórica implica ir definindo a rede de conceitos que a problemática em elaboração solicita; identificar autores e proposições férteis para laborar a construção e debruçar-se efetivamente num trabalho reflexivo sobre eles que compreende: entender aprofundadamente suas proposições, o seu tecido argumentativo; perceber os domínios contextuais e históricos em que se geraram; avaliar seu alcance e suas possibilidades para apreender o fenômeno que nos concerne na pesquisa; laborar em tentativas de alargamentos e articulações possíveis com outras propostas e conceitos no intuito de melhor apreender o fenômeno investigado.

Neste processo, pistas geradas da exploração do concreto empírico concernente à problemática (pesquisa exploratória), assim como especificidades que vão se desenhando nos movimentos de contextualização tornam-se aliados importantes no trabalho de alargamento e concretização dos conceitos.

Novamente se pode vislumbrar, neste processo, a fertilidade de movimentos de vai e vem entre o fenômeno em sua feição concreta (empírica) e os referentes teóricos que buscam pensá-los em nível de maior abstração e generalidade. A pesquisa teórica, quando assumida com força na investigação, vai possibilitando experimentar perspectivas diversas, desde onde compreender o fenômeno que se quer pesquisar e deve nos permitir chegar a um ponto de vista - multiperspectivado se acolhemos a multidimensionalidade que os fenômenos midiáticos e comunicacionais encerram - capaz de nos ajudar na sua compreensão.

Confluindo com os demais movimentos, pode caminhar rumo a um artesanato teórico que, evitando o recurso a formulações e modelos prontos, efetive-se como construção empenhada para o objeto investigado.

\section{c) Pesquisa metodológica}

Consciente ou não o pesquisador, ao iniciar um processo de pesquisa, trabalha com concepções de método, tanto num nível mais geral (teorias do conhecimento, do método científico) quanto em níveis mais específicos da sua construção (teorias dos métodos de observação, de descrição etc.). $\mathrm{O}$ domínio da fabricação da pesquisa exige do investigador não negligenciar esta dimensão. Solicita, portanto, uma empreitada de reflexão deste nível, o que implica, entre outras ações, trabalhar em movimentos de pesquisa metodológica.

Pensando a dimensão do método como lugar que responde pela fabricação do conhecimento científico nos seus diversos planos, é mister aprofundar sua concepção, pois dele depende a fecundidade do conhecimento que se quer gerar. As ações de pesquisa metodológica, neste nível, implicam investir em trabalho de reflexão de teorias do método para alicerçar a construção da investigação. Lembremos, com Bachelard (1977) e Bourdieu et al. (1999), que os métodos são, efetivamente, teorias em ato.

No plano da construção do objeto empírico, o reconhecimento da problemática da construção/captura dos fatos - pois se trata aí não de mera recolha de informações e sim de fabricação dos fatos requeridos pela problemática pela mediação dos métodos e procedimentos de investigação - solicita empenho do investigador no sentido de dominar as teorias dos métodos, lembrando que eles operam inclusões e exclusões, conferem existência científica a determinadas dimensões, obliterando a captura de outras.

Daí a necessidade de que sua construção e utilização seja norteada pela restituição da reflexão metódica sobre as condições e os limites de sua validade em termos de adequação ao objeto de investigação (BOURDIEU et al. 1999). Somente esta reflexão pode permitir e fecundar a reinvenção criadora, necessária para superar os limites e obstáculos epistemológicos contidos nestes métodos e procedimentos de investigação.

As problemáticas propõem modos de questionamento e de compreensão de um fenômeno que fazem exigências em termos do objeto empírico que buscamos capturar/fabricar/compreender - elas nos solicitam olhar dimensões ou aspectos, em cuja captura/construção intervirão os métodos e procedimentos de observação. Então, o desafio que se coloca é construir arranjos metodológicos que trabalhem em favor da captura/construção destas dimensões (BACHELARD, 1977; BOURDIEU et al. 1999; MILLS, 1975).

A pesquisa metodológica (que também se realiza na pesquisa da pesquisa) é, então, um movimento importante para alicerçar este âmbito da fabricação pensada dos objetos. Ela exige a instauração de processos de estudo, reflexão, desconstrução, reformulação e apropriação de propostas metodológicas (contidas em textos metodológicos reflexivos e em pesquisas concretas), para delas extrair elementos que possibilitem arquitetar arranjos metodológicos que respondam aos requerimentos das problemáticas com as quais estamos trabalhando. As aproximações empíricas, pela via da pesquisa exploratória, em confluência com esta prática, permitem realizar uma fabricação metodológica sensível às espe- 
cificidades do concreto. A complexidade e a multidimensionalidade dos fenômenos comunicacionais/midiáticos coloca-nos o desafio de operar, não apenas no nível teórico, mas também no metodológico, com configurações multiperspectivadas, não redutoras. A construção e experimentação de estratégias multimetodológicas em pesquisas comunicacionais tem revelado sua fertilidade neste sentido (LOPES et al., 2002; BONIN, 2001, 2004). Grosso modo, elas implicam em construir arranjos de métodos e procedimentos diversos que confluam para a fabricação de dados complexos. Na construção destes arranjos, algumas questões são importantes de serem consideradas:

- eles devem ser capazes de oferecer possibilidades de captura/construção das múltiplas dimensões requeridas pela problemática concreta;

- sua construção se vale da reflexão teórica dos métodos para dar conta do que fazem aos objetos, dos pressupostos que se instituem como configuradores destes objetos, das possibilidades que oferecem a esta captura/construção e dos limites que impõem; - esta reflexão, em convergência com as pistas advindas da pesquisa exploratória, permite obrar em processos de reinvenção, de criação e de integração com os demais métodos e procedimentos, em um desenho coerente; - o desenho busca permitir a superação de limites de um método ou procedimento por outro ou por redesenho deste método/procedimento;

- arranjos metodológicos multiperspectivados também devem possibilitar a fabricação de angulações distintas de um mesmo dado ou aspecto crucial, para fabricar um dado complexo (operações multifocais na captura/fabricação dos dados).

\section{d) Pesquisa exploratória}

Desafiada pelas reconfigurações nas dinâmicas que conformam os objetos do campo, a pesquisa em comunicação enfrenta a necessidade de construir suas problemáticas com forte atenção à dinâmica concreta dos objetos que investiga. Impõe-se a necessidade de realização de fortes movimentos de aproximação empírica para dar conta destes objetos "móveis, nômades, de contornos difusos" (Lopes, 2006). As ações de pesquisa exploratória implicam investir em planejamento, construção e realização de sucessivas aproximações ao concreto empírico, a partir de várias angulações possíveis - angulações que interessam ao problema/objeto em construção. Os procedimentos de pesquisa exploratória podem ser diversos, desde o recurso a dados secundários até a observação direta de fenômenos empíricos concernentes à problemática investigada.

A pesquisa exploratória traz contribuições importantes para a construção investigativa. As pistas relativas ao(s) fenômeno(s) geradas através dela facilitam a construção e a concretização dos problemas/objetos investigados; permitem trabalhar na construção de configurações teóricas sensíveis aos objetos concretos da realidade comunicacional; suscitam o aprofundamento de dimensões teóricas que se revelam importantes na configuração do concreto. A pesquisa exploratória oportuniza experimentar, vivenciar e testar métodos e procedimentos para compor e construir arranjos metodológicos sensíveis às demandas da problemática e das lógicas dos objetos empíricos. Auxilia na construção das amostras e, ou corpus a serem focalizados na investigação sistemática Exercícios multi-angulados de aproximação empírica são importantes porque aguçam a percepção de dimensões dos objetos naturalizadas ao olhar - pela possibilidade de distanciamento/estranhamento que potencializam (BONIN, 2006, MALDONADO, 2002a) ${ }^{7}$.

\section{e) A pesquisa de contextualização}

Para apreender os objetos comunicacionais/midiáticos em suas relações com a realidade concreta em que estão inseridos e que participam da sua configuração, faz-se necessário trabalhar na construção de contextualizações relevantes para a problemática investigada. Maldonado (2006), refletindo sobre esta dimensão na pesquisa em comunicação, oferece-nos elementos importantes para pensar este movimento, que busco aqui retomar. Conforme propõe este autor, o contexto é parte constitutiva e decisiva da formulação do problema, ele define as relações do objeto investigado com a realidade na qual está inserido. A contextualização é importante porque evita que a pesquisa se reduza a um exercício abstrato, sem vínculo com a realidade e com o mundo.

Na pesquisa comunicacional, é importante saber formular e construir o complexo estrutural que dá conta do contexto midiático e comunicacional e que configura a sua particularidade. A contextualização permite ter uma visão abrangente e, ao mesmo tempo, particular do fenômeno investigado. Para realizar este movimento de contextualização, faz-se necessário trabalhar em práticas que possibilitem ir construindo os múltiplos contextos que participam efetivamente da problemática em construção. Aproximações à realidade, vivências, investigação teórica (busca de subsídios de outras pesquisas que produziram conhecimentos sobre estes contextos), aliadas à reflexão, análise e sistematização de elementos importantes para a compreensão do problema/objeto investigado são operações importantes na construção deste movimento.

A importância da contextualização pode ser vislumbrada, por exemplo, nas anotações de Mills (1975) sobre suas práticas no diário de investigação. Pesquisas comunicacionais relevantes que temos acompanhado têm demonstrado a força eimportância destemovimento decontextualização para compreender os fenômenos na sua concretude e nas relações com seus contextos configuradores ${ }^{8}$.

Essas reflexões mais que fornecer elementos conclusivos, almejam contribuir para a reflexão sobre práticas na processualidade concreta da investigação. Pensar sobre tais práticas éfundamental, visto que elas materializam, expressame constituem as complexas lógicas que orientam a construção do conhecimento dos objetos da Comunicação wFamEcos 


\section{NOTAS}

1 No texto Nos bastidores da pesquisa: a instância metodológica experienciada nos fazeres e nas pro-cessualidades de construção de um projeto (BONIN, 2006), explorei algumas das práticas (pesquisas exploratória, metodológica e da pesquisa) para pensar seu lugar na elaboração de um projeto de pesquisa amadu-recido. Busco retomar e avançar na reflexão daquelas práticas como também contem-plar outras (pesquisas teórica e de contextualização), pensando-as como constitutivas do processo de construção da pesquisa comunicacional.

2 Bachelard (1977) sublinha a necessidade de inscrever o domínio da reflexão no interior da prática científica, de instaurar processos de vigilância epistemológica no coração da fabricação do conhe-cimento, para submeter as construções que fazemos a uma retificação permanente.

3 É interessante lembrar que a Comunicação surge num momento de questionamento das divisões disciplinares instituídas no processo de institu-cionalização e das Ciências Sociais, quando se verifica um esforço de designar novas áreas cujos objetos reclamam construções "interdis-ciplinares", conforme o relatório da Comissão Gulbenkian para a reestruturação das Ciências Sociais (WALLERSTEIN, 2006). $\mathrm{Ou}$, como especifica Lopes (2006, p.27), "os desafios trazidos pela compreensão de novos objetos, como é o da Comunicação, encaminham para a formação de novas sínteses disciplinares ou convergências disciplinares, istoé, transdisciplinas ou pós-disciplinas".

4 Destaco como experiências relevantes para o desenvolvimento das propostas deste artigo as seguintes: a participação no projeto coletivo Recepção de telenovela, uma exploração metodológica coordenado por Maria Immacolata $V$. Lopes (a pesquisa realizada neste subprojeto foi publicada em LOPES et al. 2002); a atuação em disciplinas relativas à metodologia da pesquisa em comunicação nos âmbitos da graduação, do mestrado e do doutorado; as orientações de TCCs, dissertações e teses; o trabalho desenvolvido no grupo de pesquisa PROCESSOCOM, do qual sou parte e que se dedica, entre outras questões, à reflexão, prática e experimentação de metodologias em pesquisas comunicacionais. Experimentações metodológicas realizadas, discutidas e sistematizadas pelos membros do grupo foram publicadas em Maldonado et al. (2006).

5 No livro Metodologias na pesquisa em comunicação: olhares, trilhas e processos (Maldonado et al. 2006), trabalhamos um texto que reflete sobre a pesquisa da pesquisa, a pesquisa exploratória e a pesquisa metodológica. O texto de Maldonado, que integra este livro, reflete sobre a pesquisa teórica, de contextualização e empírica; o de Bonin, do mesmo livro. Neste texto retomo algumas das formulações ali realizadas, procurando trabalhá-las em conjunto e trazendo outros elementos para a discussão.

6 Na pesquisa Telenovela Identidade étnica, cotidiano familiar e telenovela, por mim realizada, a pesquisa da pesquisa foi de suma importância para alimentar a projetação e realização de um arranjo metodológico para a coleta de dados pautado numa estratégia multimetodológica.

7 Ver, a título de exemplo, pesquisas realizadas por Santos (2005), Schmitz (2007), Cruz (2007), Iser (2006) e Marin (2006a e 2006b), integrantes do grupo Processocom, que trabalharam fortes movimentos de pesquisa exploratória para configu-rar seus problemas/objetos; para construir, viven-ciar e testar procedimentos metodológicos que foram a base para desenhos inventivos de procedimentos nas etapas sistemáticas de ob-servação.

8 Ver, por exemplo, as pesquisas de Santos (2005), Schmitz (2007) e Marin (2006a).

\section{REFERÊNCIAS}

BACHELARD, Gaston. A epistemologia. R J: Zahar, 1977.

BONIN, Jiani Adriana. Identidade étnica, cotidiano familiar e telenovela. 2001. $410 \mathrm{f}$. Tese (Doutorado em Ciências da Comunicação) - ECA, USP, 2001.

Identidade étnica e telenovela. Ciberlegenda. Rio de Janeiro, n.9, p.1-25, 2002. Disponível em: <http// www.ciberlegenda.br> Acesso em: 19/08/2007.

Estratégia multimetodológica de captação de dados em pesquisa de recepção: a experiência da investigação Telenovela, identidade étnica e cotidiano familiar. Rastros. Joinville, n.5, p.6-18, 2004.

Nos bastidores da pesquisa: a instância metodológica experienciada nos fazeres e nas processualidades de construção de um projeto. In: MALDONADO et. al. Metodologias da pesquisa em comunicação: olhares, trilhas e processos. Porto Alegre: Sulina, 2006a. p.271-294.

BOURDIEU, Pierre et al. A profissão de sociólogo. Preliminares epistemológicas. 2. ed. Petrópolis, RJ: Vozes, 1999. $328 \mathrm{p}$.

CERTEAU, Michel de. A invenção do cotidiano: 1. Artes de fazer. Petrópolis, RJ: Vozes, 1994. 351 p.

CERTEAU, Michel de; GIARD, Luce; MAYOL, Pierre. A 
invenção do cotidiano: 2. Morar, cozinhar. Petrópolis, RJ: Vozes, $1996.372 \mathrm{p}$.

CRUZ, Fernanda Guimarães. Socialização midiatizada: o papel da televisão na recepção de adolescentes de instituições de acolhimento. São Leopoldo, 2007. 331 f. Dissertação (Mestrado) - Programa de Pós Graduação em Ciências da Comunicação, Unisinos.

GIARD, Luce. História de uma pesquisa. In: CERTEAU, Michel de. A invenção do cotidiano: 1. Artes de fazer. Petrópolis, RJ: Vozes, 1994. p.9-32

IANNI,Octávio. As ciências sociais na época da globalização. Revista Brasileira de Ciências Sociais, SP, v.13, n.37, p.33-41, 1998. Disponível em: <http:// www.scielo.br/scielo.php?script $=$ sci

- $\quad$ arttext\&pid=S0102-69091998000200002\&

lng=en\&nrm=iso >. Acesso em: 03 de maio de 2008.

ISER, Fabiana. Pesquisa exploratória: a relevância da aproximação empírica para as definições da pesquisa. In: MALDONADO et. al. Metodologias da pesquisa em comunicação: olhares, trilhas e processos. Porto Alegre: Sulina, 2006a. p.193-216.

LOPES, Maria Immacolata V. Pesquisa em Comunicação: formulação de um modelo metodológico. São Paulo: Loyola, 1990.148 p.

. O campo da comunicação: sua constituição, desafios e dilemas. Revista Famecos. Porto Alegre, n.30, p.16-30, ago. 2006.

LOPES Maria Immacolata V. et al. Vivendo com a telenovela. Mediações, recepção, teleficcionalidade. São Paulo: Summus, 2002. $394 \mathrm{p}$.

MALDONADO, Efendy. Produtos midiáticos, estratégias, recepção. A perspectiva transmetodológica. Ciberlegenda. Rio de Janeiro, n.9. p. 1-15 2002a. Disponível em: <www.uff.br/mestcii/efendy2.htm.> Acesso em 20/08/2007.

. Explorações sobre a problemática epistemológica no campo das ciências da comunicação. Ciberlegenda. Rio de Janeiro, n.10, p. 1-16, 2002b. Disponível em <www.uff.br/mestcii/efendy3.htm.> Acesso em 21/ 08/2007.

. Práxis teórico/metodológica na pesquisa em comunicação: fundamentos, trilhas e saberes. In: MALDONADO et. al. Metodologias da pesquisa em comunicação: olhares, trilhas e processos. Porto Alegre: Sulina, 2006. p.271-294.

MARIN, Elizara Carolina. Entretenimento televisivo: pes- quisa do produto e da recepção dos programas de auditório Domingão do Faustão (Rede Globo) e Domingo Legal (SBT). São Leopoldo, 2006a. 285 f. Tese (Doutorado) Programa de Pós Graduação em Ciências da Comunicação, Unisinos.

. O ofício da pesquisa: processos do fazer. In: MALDONADO et. al. Metodologias da pesquisa em comunicação: olhares, trilhas e processos. Porto Alegre: Sulina, 2006b. p.65-90.

MARTÍN BARBERO, Jesús. Razón técnica e razón política: espacios/tempos no pensados. Revista latinoamericana de ciencias de la comunicación. São Paulo, n.1, p.22-37, ago./dez., 2004.

MATA, María Cristina. De la cultura massiva a la cultura mediática. Diálogos de la comunicación. Lima, n. 56, p. 80-91, out. 1999. Disponível em <www.felafacs.org/dialogos>. Acesso em: 01/09/ 2007.

MILLS, C. Wright. A imaginação sociológica. 4. ed. Rio de Janeiro: Zahar, 1975.

SANTOS, Airton Ricardo Tomazzoni dos. No embalo do videoclipe: a dança midiatizada na televisão e a recepção do público adolescente. São Leopoldo, 2005. 304 f. Dissertação (Mestrado) - Programa de Pós Graduação em Ciências da Comunicação, Unisinos.

SCHMITZ. Mulher na moda: recepção e identidade feminina nos editoriais de moda da revista Elle. São Leopoldo, 2007. 356 f. Dissertação (Mestrado) - Programa de Pós Graduação em Ciências da Comunicação, Unisinos.

SODRÉ, Muniz. Eticidade, campo comunicacional e midiatização. In. MORAES, Denis (org.). Sociedade midiatizada. Rio de Janeiro: Mauad, 2006. p.19-32.

VERÓN, Eliseo. Esquema para el analisis de la mediatizacion. Diálogos de la comunicación. Lima, n.48, p.9-17, 1997. Disponível em $<$ www.felafacs.org/dialogos>. Acesso em: 18/ 07/2007. 